\title{
Activation of the mouse oxytocin promoter by the orphan receptor $\mathrm{ROR} \alpha$
}

\section{K Chu and $\mathbf{H} \mathbf{H}$ Zingg}

\author{
Laboratory of Molecular Endocrinology, Royal Victoria Hospital Research Institute, McGill University, \\ Montreal, Quebec, Canada H3A 1A1
}

(Requests for offprints should be addressed to H H Zingg, Laboratory of Molecular Endocrinology, 687

Pine Avenue West, Room H7.63, Montreal, Quebec, Canada H3A 1A; Email: zingg@rvhri.lan.mcgill.ca.)

\begin{abstract}
Although an increasing number of nuclear orphan receptors have recently been identified, the number of known naturally occurring genes that are directly regulated by orphan receptors is still small. We have shown previously that the gene encoding the neuropeptide oxytocin (OT) is negatively regulated by the orphan receptors chicken ovalbumin upstream transcription factor I (COUP-TFI) and II. Here we show that the mouse OT gene promoter is activated by $\mathrm{ROR} \alpha$, a representative of the ROR/RZR orphan receptor subfamily. Using promoter/chloramphenicol acetyltransferase reporter constructs in heterologous transfection assays, we determined that ROR $\alpha$ action induces a $<6$-fold increase in promoter activity. By $5^{\prime}$ and $3^{\prime}$ deletion analysis, DNase footprint analysis and
\end{abstract}

electrophoretic mobility shift assays, we found that ROR $\alpha$ action is mediated by two $14 \mathrm{bp}$ regions centered at 160 and 180 nucleotides upstream of the transcriptional initiation site. Both sites contain significant sequence identities with an established ROR recognition sequence. Mutations in either or both of these sites reduce significantly ROR $\alpha$ induced activation of the OT promoter. In view of the strong transcriptional activation exerted by ROR $\alpha$ on the OT gene promoter and the widespread distribution of different members of the ROR/RZR family, interactions between ROR/RZR isoforms and the OT gene may form part of the multifactorial regulatory mechanisms that control OT gene expression in different tissues.

Fournal of Molecular Endocrinology (1999) 23, 337-346

\section{INTRODUCTION}

The nonapeptide hormone oxytocin (OT) acts as a neurotransmitter as well as a peripheral hormone. Whereas central effects of OT involve induction of specific reproductive behaviors, peripheral effects include uterine contractions, milk ejection, natriuresis and vasodilation (Zingg 1996, Thibonnier et al. 1999). Centrally, the OT gene is expressed in specific hypothalamic neuroendocrine cells as well as in the pineal gland (Milcu et al. 1963, Fisher \& Fernstrom 1981, Liu \& Burbach 1987). Peripherally, the gene is expressed in uterine epithelium (Lefebvre et al. 1992), fetal membranes (Mitchell et al. 1998) and the corpus luteum (Ivell et al. 1998). OT gene expression is hormonally induced by estrogen and retinoic acid (Larcher et al. 1995). In addition, we and others have shown that orphan nuclear receptors, specifically members of the chicken ovalbumin upstream transcription factor (COUP-TF) family, antagonize hormonemediated transcriptional activation of the OT gene and actively silence the $\mathrm{OT}$ gene promoter (Burbach et al. 1994, Chu \& Zingg 1997, Chu et al. 1997). These nuclear receptor/promoter interactions are mediated by a well-conserved region centered at -160 relative to the transcriptional initiation site (Richard \& Zingg 1990, Adan et al. 1993). This region was initially identified as an estrogen response element (ERE) (Richard \& Zingg 1991) and is here referred to as OT/ERE.

In the present study, we have examined the role of the recently identified orphan receptor $\mathrm{ROR} \alpha$ in the regulation of the OT promoter. The ROR/RZR subfamily of orphan nuclear receptors is a recent addition to the nuclear receptor family and comprises the following members: ROR $\alpha 1$, ROR $\alpha 2$, ROR $\alpha 3, \operatorname{ROR} \beta / \operatorname{RZR} \beta$ and ROR $\gamma$ (Carlberg et al. 1994, Giguère et al. 1994, Hirose et al. 1994). The members of this subfamily bind as monomers 
preferentially to an AGGTCA core motif preceded by an A/T-rich region (Giguère et al. 1994). Although the expression pattern of this receptor family is quite ubiquitous, high expression of specific members is observed in certain tissues. Thus, ROR $\alpha 1$ is highly expressed in Purkinje cells of the mouse cerebellum (Matsui et al. 1995), and a mutation in the RORa1 gene gives rise to the staggerer mouse phenotype (Hamilton et al. 1996, Dussault et al. 1998). ROR $\beta / R Z R$ is abundantly expressed in the hypothalamus, the pineal gland and the thalamus (Becker-Andre et al. 1994). ROR $\gamma$ is highly expressed in skeletal muscle and may play a role in muscle development (Hirose et al. 1994).

Although structural information on the orphan receptor superfamily is rapidly expanding, relatively few genes have been identified that are directly regulated by orphan receptors. Identified target genes for members of the ROR/RZR family include the gene for $\gamma \mathrm{F}$-crystallin, apoliprotein A-I, 5 -lipoxygenase, cellular retinol-bindingl protein, retinoic acid receptor- $\beta, \mathrm{p} 21^{\mathrm{WAF} / \mathrm{CIP} 1}$ and Purkinje cell protein-2 (Steinhilber et al. 1995, Tini et al. 1995, Schräder et al. 1996, Vu-Dac et al. 1997). Here we report that the mouse OT gene represents a novel target for ROR receptors by demonstrating that its promoter is strongly stimulated by ROR $\alpha$ via a DNA element that has been conserved throughout species evolution.

\section{MATERIALS AND METHODS}

\section{Plasmids}

Plasmid p1064CAT contained nucleotides - 1064 to +38 of the mouse OT promoter (Hara et al. 1990) linked to the gene encoding chloramphenicol acetyltransferase (CAT). The deletion mutants p428CAT, p225CAT, p118CAT and p42CAT were derived from p1064CAT. p225 OOT/ERE, p $225 \Delta \mathrm{HS} 1$ and p $225 \Delta \Delta$ mutants were obtained by site-directed mutagenesis (Kunkel 1985). The mutagenic oligonucleotides were also used in the gel shift assays (see below). Plasmids p225/118-TATACAT and p134/34-TATA-CAT contained fragments -225 to -118 and -134 to -34 respectively of the mouse OT $5^{\prime}$-flanking region linked to a TATA-box derived from the adenovirus $1 \mathrm{~b}$ followed by the gene encoding CAT. The parent plasmid $\beta$-CAT containing the TATA-box linked to the CAT gene was obtained from Dr V Giguère, (Royal Victoria Hospital, McGill University, Montreal). All constructs were verified by dideoxynucleotide sequencing. Expression vectors CMX and CMX-ROR 11 were also obtained from Dr Giguère (Giguère et al. 1994). These contained a cytomegalovirus-derived promoter which, in CMXROR $\alpha 1$, was linked to a cDNA encoding mouse ROR $\alpha 1$. The vector HSP- $\beta$-gal contained a heat shock protein (HSP) gene-derived promoter linked to the $\beta$-galactosidase gene (obtained from Dr Giguère).

\section{Transfections}

Mouse Neuro-2a cells (American Type Culture Collection, Rockville, MD, USA; line CCL 131) were maintained in Eagle's minimum essential medium (EMEM; Sigma, St Louis, MI, USA) supplemented with $10 \%$ fetal bovine serum (GIBCO, Rockville, MD, USA). Cells were plated on $60 \mathrm{~mm}$ dishes and allowed to reach 70-80\% confluency before transfection. Plasmids used in transfection studies were purified twice by ultracentrifugation through $5 \cdot 2 \mathrm{M}$ cesium chloride. Each plate was transfected with a total of $10 \mu \mathrm{g}$ DNA, including $5 \mu \mathrm{g}$ CAT reporter plasmid, $3 \mu \mathrm{g}$ expression vectors, $100 \mathrm{ng}$ HSP- $\beta$ galactosidase plasmid and $1.9 \mu \mathrm{g}$ pBluescript plasmid $\mathrm{KS}(+)$. Transfection was performed by the calcium phosphate precipitation technique. After $4 \mathrm{~h}$ of incubation with the precipitate, a glycerol shock was applied by incubating cells in a buffered saline solution containing $15 \%$ glycerol for $2.5 \mathrm{~min}$. Cells were then washed with PBS and cultured in EMEM/10\% fetal bovine serum. Forty-eight hours after the transfection, cells were collected and CAT activity was determined, using a phase extraction method (Seed \& Sheen 1988). Unless stated otherwise, transfections were performed in duplicates at least three times. CAT activity was normalized with respect to $\beta$-gal activity recovered from cell extracts. Cotransfection with the ROR 1 expression vector remained without effect on the transcriptional activity of the HSP- $\beta$-gal expression vector.

\section{Bacterial expression of proteins}

Recombinant human ROR $\alpha 1$ and rat COUP-TFII were produced in BL21 cells as glutathione-Stransferase (GST)-fusion proteins. The cDNAs encoding human ROR $\alpha 1$ or rat COUP-TFII were amplified by PCR and inserted in-frame with the GST-coding region in the bacterial expression plasmid pGEXKG (Novagen, Madison, WI, USA). The resulting plasmid was used to transform BL21 cells as described (Novagen). Cells were grown until they reached an $\mathrm{OD}_{550}$ of 0.6 and Isopropyl- $\beta$-Dthiogalactopyranoside (IPTG) was added to a final concentration of $0.1 \mathrm{mM}$. Three hours after IPTG induction, cells were collected and purified using a glutathione resin (Pharmacia, Uppsala, 
Sweden), according to the manufacturer's instructions. Finally, the GST moiety was removed by thrombin cleavage

\section{DNAse I footprinting assays}

Probes for DNAse footprinting experiments were generated by PCR. The primer pair used for the amplification reaction consisted of oligonucleotide R48 (complementary to a part of the pBluescript polylinker region, sense strand direction) and a reverse primer complementary to the $5^{\prime}$-end of the CAT cDNA (anti-sense direction). The oligonucleotide R48 was labeled with ${ }^{32} \mathrm{P}$ using $\left.{ }^{32} \mathrm{P}\right] \gamma \mathrm{ATP}$ and $\mathrm{T} 4$ polynucleotide kinase. For the $\mathrm{PCR}$ reaction, $\mathrm{p} 225 \mathrm{CAT}$ was used as a template in conjunction with $10 \mathrm{pmol}$ of each primer. Following 35 cycles of amplification $\left(94{ }^{\circ} \mathrm{C}, 1 \mathrm{~min}\right.$; $\left.58{ }^{\circ} \mathrm{C}, 1 \mathrm{~min} ; 72^{\circ} \mathrm{C}, 1 \mathrm{~min}\right)$ the PCR product was gel purified and diluted to 10000 c.p.m. $/ \mathrm{ml}$. For DNase I footprinting analysis, 0.06-5 ml of recombinant protein were incubated with 10000 c.p.m. DNA probe in binding buffer (12 mM Hepes (pH 7.9) 12\% glycerol, $70 \mathrm{mM} \mathrm{KCl,}$ $3 \mathrm{mM} \mathrm{MgCl}_{2}, 250 \mathrm{ng}$ poly(dI-dC); Pharmacia). Following incubation of the binding reaction for $30 \mathrm{~min}$ at room temperature, $0 \cdot 25$ unit of DNAse I (RQ1-DNase I, Promega, Madison, WI, USA) was added for $90 \mathrm{~s}$. The endonuclease reaction was stopped by the addition of EDTA to a final concentration of $5 \mathrm{mM}$. The binding reaction was phenol extracted, precipitated with ethanol and resuspended in $90 \%$ formamide loading buffer. Equal amounts of recovered probe were then loaded on a $10 \%$ denaturating polyacrylamide gel.

\section{Electrophoretic mobility shift assay (EMSA)}

For EMSAs, in vitro translated CMX or CMXROR $\alpha 1$ was used. Translation products were obtained in vitro by using plasmids CMX or CMX-ROR $\alpha$ as templates in an in vitro transcription/translation reaction mix (TNT lysate, Promega) according to the manufacturer's instruction. All proteins were $\left[{ }^{35} \mathrm{~S}\right]$ methionine labeled and their sizes verified by electrophoresis in $10 \%$ SDS-polyacrylamide gels.

Ten picomoles double-stranded oligonucleotides were labeled using T4 kinase and $\left[{ }^{32} \mathrm{P}\right] \gamma \mathrm{ATP}$. Two milliliters of in vitro translated $\mathrm{ROR} \alpha 1$ were incubated in binding buffer with $10 \mathrm{fmol}$ probe for $30 \mathrm{~min}$ at room temperature and electrophoresed on a non-denaturating $4 \%$ polyacrylamide gel in $0 \cdot 25 \times$ TBE buffer at $150 \mathrm{~V}$. A polyclonal antibody against rat ROR $\alpha 1$ was obtained from Dr V Giguère (Dussault et al. 1998).

\section{RESULTS}

We tested the effect of ROR $\alpha 1$, a member of the family of orphan receptors, on OT promoter activity by transfecting $5^{\prime}$ deletion mutants of mouse OT-CAT reporter plasmids in mouse Neuro-2a cells in conjunction with an expression plasmid for ROR $\alpha 1$ (CMX-ROR $\alpha 1$ ). With the longest reporter construct used (p1064CAT), cotransfection of the ROR $\alpha 1$ expression vector CMX-ROR $\alpha 1$ led to a 6to 7 -fold increase in CAT activity compared with cells transfected with the parental plasmid CMX (Fig. 1). Similar or greater activation was also observed with shorter constructs ( $\mathrm{p} 428 \mathrm{CAT}$ and p225CAT). However, with the construct p118CAT, ROR 1 elicited only a $2 \cdot 2$-fold increase in activity. No significant activation was observed with the construct p42CAT. These studies indicate that the sequence interval -225 and -42 harbors a region involved in conferring inducibility by $\mathrm{ROR} \alpha$.

To delineate further the 3 '-end of the area mediating this response, regions -225 to -118 (p225/118TATA-CAT) and -134 to -34 (p134/ 34TATA-CAT) were cloned upstream of a minimal adenovirus 1b TATA-box/CAT reporter and transfected in Neuro-2a cells (Fig. 2). Cotransfection of ROR $\alpha 1$ elicited a strong 14-fold increase in CAT activity mediated by the construct p225/ 118TATA-CAT. Only a very weak effect was observed with p134/42TATA-CAT or the parental reporter construct $(\beta-\mathrm{CAT})$. These results narrow the area mediating activation by ROR $\alpha 1$ further down to the region -225 to -118 .

DNAse I footprinting with bacterially expressed ROR $\alpha 1$ was used to identify more precisely the regions involved in ROR $\alpha 1$ binding. Two adjacent regions were found to be resistant to DNAse I digestion following incubation with ROR $\alpha 1$ (Fig. 3). One region was centered at position -180 and the other at position -160 . The first region $(-188$ to -174$)$ includes the sequence element AGGTCA. As shown by Umesono et al. (1991), this element forms the building block of several types of nuclear receptor response elements (see Discussion). The second region encompasses the OT/ERE and contains three AGGTCA-related motifs, which can be viewed either as an inverted repeat (HS2 and HS3) or as a direct repeat (HS3 and HS4) (Fig. 4A). The center of the footprint appeared to be located over HS4 (Fig. 3).

For comparison, the binding of the orphan receptor COUP-TFII to this same promoter area was also examined. COUP-TFII is a prototype for dimer binding. We have previously shown that COUP-TFII binds to the human OT/ERE (Chu et al. 1997). Lane 4 in Fig. 3 shows that bacterially 

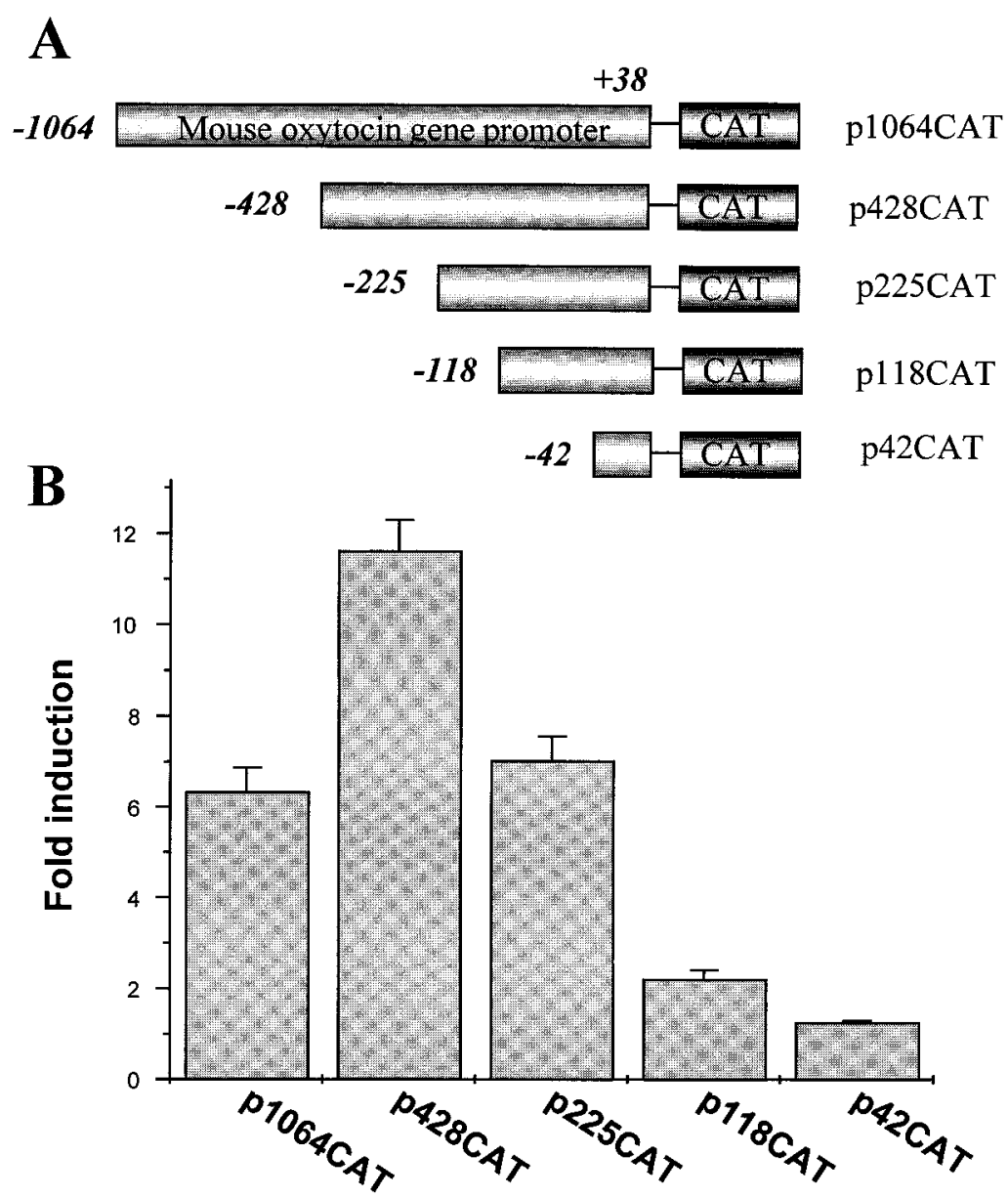

FIGURE 1. Activation of the mouse OT promoter by ROR $\alpha 1$. (A) Schematic diagram of constructs used. Different length segments of the 5 '-flanking region of the mouse OT gene were linked to the structural gene for CAT. Sequence positions are indicated with respect to the transcriptional initiation site. (B) The constructs shown in (A) were transfected in mouse Neuro-2a cells together with a lacZ expression vector and the parent expression vector CMX or the ROR 1 expression vector CMX-ROR $\alpha$. CAT activity was determined in cell extracts and was normalized with respect to $\beta$-gal activity. ROR $\alpha 1$-mediated transcriptional activation was expressed as the ratio of CAT activity in cells transfected with vector CMX-ROR $\alpha$ vs cells transfected with the parent expression vector CMX. Each bar represents the mean \pm s.E. of three or more independent experiments, each performed in duplicate.

expressed COUP-TFII also binds to the mouse OT/ERE and HS1, but the regions protected by COUP-TFII are larger than the ones protected by ROR $\alpha 1$. This is compatible with the accepted concept that COUP-TF binds as a dimer, whereas ROR $\alpha$ binds as a monomer. Indeed, COUP-TF homodimers have been shown to bind with high affinity to monomeric ROR/RZR response elements (Schräder et al. 1996). In addition, COUP-TFII is also able to bind to a more downstream area $(-75$ to -100) containing three (inverted) GGTCA repeats (Fig. 3) as demonstrated earlier for the human gene (Chu et al. 1997). A noticeable but weak footprint is also formed by $\mathrm{ROR} \alpha$ in this region.

EMSA was performed to further characterize ROR $\alpha 1$ binding to the OT/ERE and the HS1. In vitro translated $\mathrm{ROR} \alpha 1$ protein was incubated with oligonucleotides encompassing either the OT/ERE (Fig. 4B) or the HS1 (Fig. 4C). ROR 1 readily 


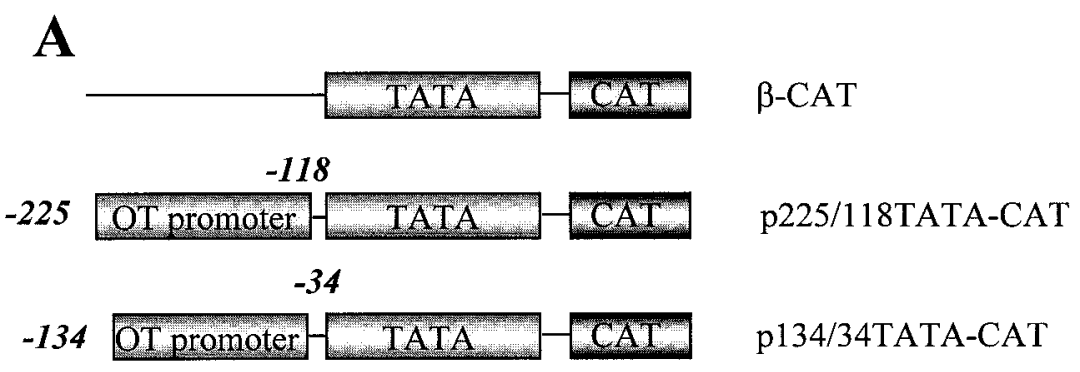

B

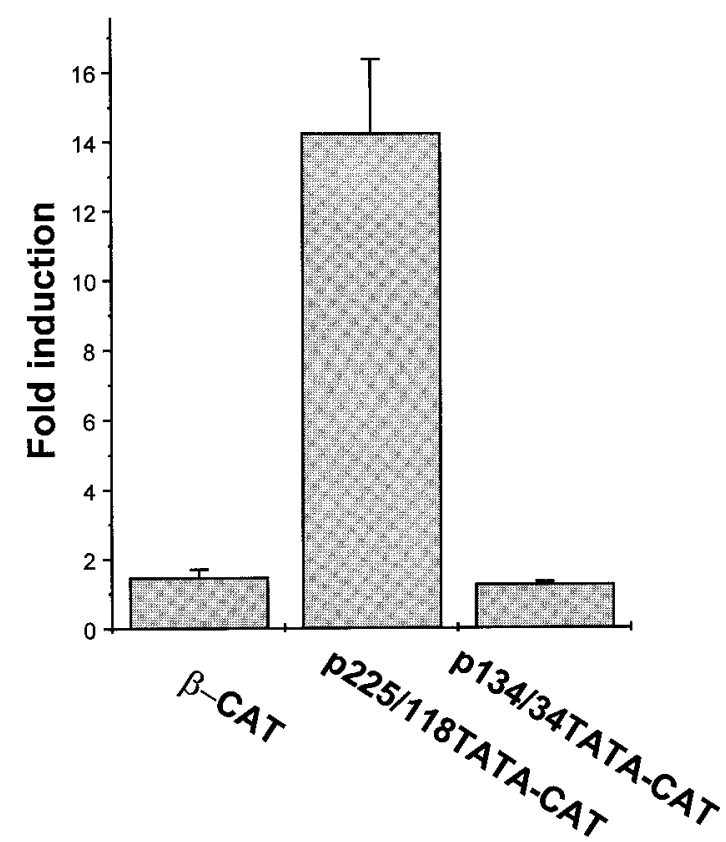

FIGURE 2. The region -225 to -118 of the OT promoter is sufficient for ROR $\alpha 1$-mediated activation. (A) Schematic diagram of constructs used. Regions -225 to -118 (p225/118TATA-CAT) and -134 to -34 (p134/34TATA-CAT) were cloned upstream of the adenovirus $1 \mathrm{~b}$ TATA-box and transfected into Neuro-2a cells together with the vector CMX or CMX-ROR $\alpha 1$. (B) CAT activity was normalized with respect to $\beta$-gal activity and was expressed as fold induction observed in CMXROR $\alpha$-transfected cells over CMX-transfected cells, as in Fig. 1. Each bar represents the mean \pm s.E. of three or more independent experiments, each performed in duplicate.

bound specifically to the OT/ERE (Fig. 4B, lanes 3-6). In contrast to the wild-type OT/ERE oligonucleotide, an oligonucleotide carrying a mutated OT/ERE $(\triangle \mathrm{OT} / \mathrm{ERE})$ was unable to compete for binding (lanes 4-6 vs 7-9). ROR $\alpha 1$ binding to the OT/ERE probe was also competed by an oligonucleotide containing HS1 (lanes 10-12). The consensus RORE represented an even stronger competitor. Whereas a 25 -fold excess of cold RORE oligonucleotide readily competed away binding of the OT/ERE or the HS1 probes, a 100-fold excess of homologous cold probe was required to observe the same effect (Fig. 4B and C).

We next tested mutations that abrogate ROR $\alpha$ binding with respect to their effect on promoter function. The construct p255 $\Delta$ OT/ERE-CAT carried the mutation present in the oligonucleotide $\triangle O T / E R E$ used in the EMSA studies above. Similarly, the mutations in construct p225 $\Delta$ HS1CAT corresponded to the mutations in the 


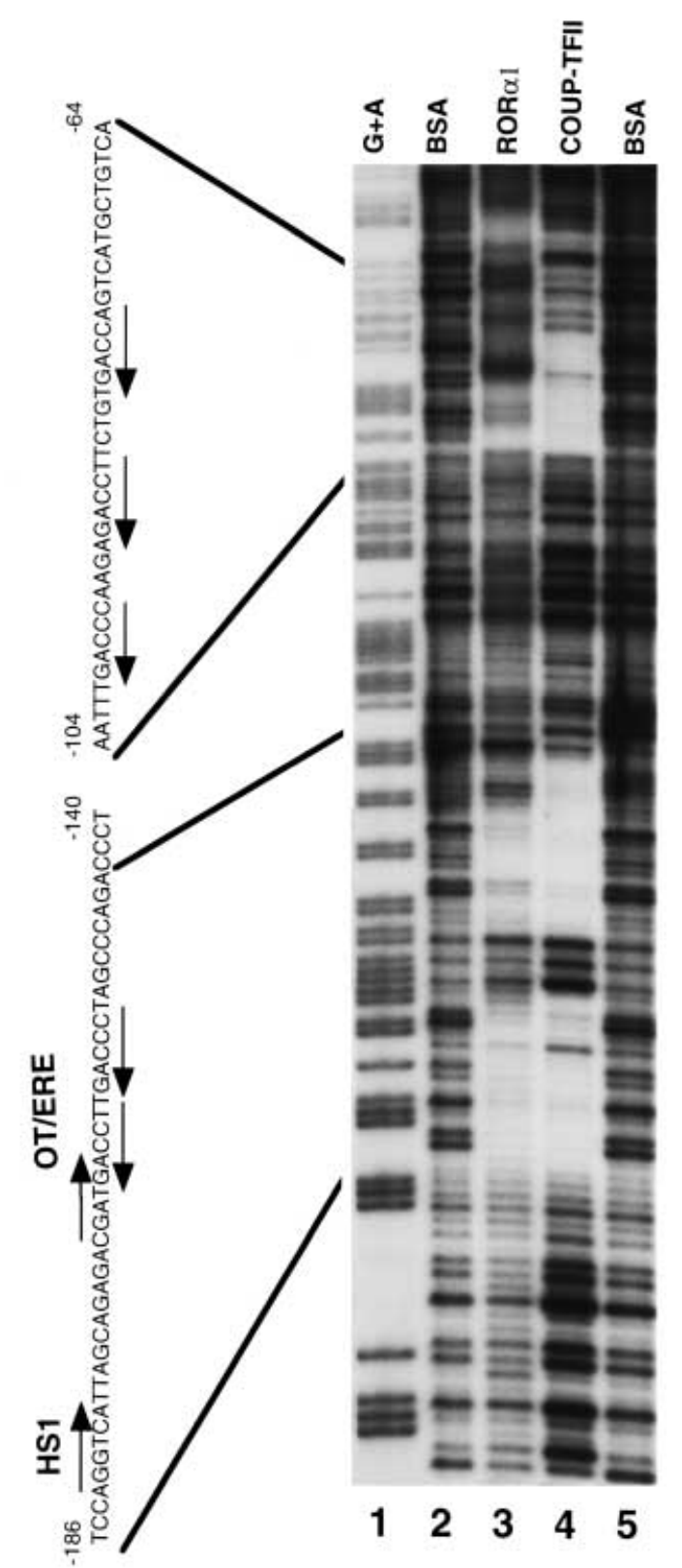

FIGURE 3. DNaseI footprinting analysis of ROR $\alpha 1$ binding sites on the mouse OT gene promoter. Recombinant human ROR $\alpha 1$ (lane 3 ) and rat COUPTFII (lane 4) were used in conjunction with a $5^{\prime}$-end (sense strand)-labeled 320 bp O'T promoter fragment. BSA: BSA was used instead of recombinant protein. $\mathrm{G}+\mathrm{A}$ : Maxam-Gilbert sequencing ladder $(\mathrm{G}+\mathrm{A}$ reaction). Relevant sequence portions are indicated on the left (sense strand).

oligonucleotide $\Delta$ HS1. Finally, the construct p255 $\Delta \Delta-$ CAT contained the combined mutations of $\Delta \mathrm{HS} 1$ and $\Delta \mathrm{OT} / \mathrm{ERE}$. Whereas wild-type
p225CAT activity was stimulated 9-fold by ROR $\alpha 1$, the mutant p225 $\Delta$ OT/ERE-CAT was only stimulated 4-fold (Fig. 5). Similarly, construct p225 $\Delta$ HS1-CAT was only induced 3-fold (Fig. 5). Introduction of a double mutation (p225 $\Delta \Delta$-CAT) led to a further decrease in inducibility to about 2 -fold. These results suggest that the OT/ERE and the HS1 sites both contribute additively, but not synergistically, to ROR $\alpha 1$-mediated induction.

\section{DISCUSSION}

We and others have shown that selected members of the nuclear receptor family are potent regulators of OT expression. This includes the nuclear receptors for estrogens, retinoids and thyroid hormone, as well as the orphan receptors COUP-TFI, COUP-TFII, Erb-A-related receptor 2 (Ear-2) and steroidogenic factor 1 (SF-1) (Richard \& Zingg 1990, 1991, Adan et al. 1992, 1993, Burbach et al. 1994, Wehrenberg et al. 1994). Here we demonstrate that a member of the orphan receptor family $\mathrm{ROR} / \mathrm{RZR}$ acts as a regulator of OT expression. In contrast to all other orphan receptors that have so far been shown to act as inhibitors or, in the case of $\mathrm{SF}-1$, as only weak activators of the OT gene promoter (Wehrenberg et al. 1994), ROR $\alpha 1$ acts as a strong activator of the OT gene promoter.

We have demonstrated that the OT promoter is stimulated by the orphan receptor $\mathrm{ROR} \alpha 1$ via a small region of the promoter which can be transferred to a heterologous adenovirus $1 \mathrm{~b}$ TATA promoter. This small region contains the conserved OT/ERE and an AGGTCA half-site (HS1) located $5^{\prime}$ of the OT/ERE. Mutation of any of these elements leads to reduced activation by ROR $\alpha 1$. In addition, using DNase I footprinting and EMSA experiments, ROR $\alpha 1$ was shown to bind specifically to these two elements.

By PCR-mediated site selection, Giguère et al. (1994) have determined a consensus sequence for RORa1 binding as follows: $\left({ }^{\mathrm{A}} / \mathrm{G} / \mathrm{T}\right)^{\mathrm{T}} / \mathrm{A}_{\mathrm{A}}^{\mathrm{A}} / \mathrm{T}_{\mathrm{T}}^{\mathrm{T}} /{ }_{\mathrm{A}} \mathrm{C}^{\mathrm{T}} / \mathrm{A}$ AGGTCA (Fig. 6). The OT/ERE contains three half-sites, HS2, HS3 and HS4 (Fig. 6). According to the results from our footprinting studies, HS4 seems to be preferentially recognized by ROR $\alpha 1$. Comparison of HS4 with the consensus ROR 1 1binding site indicates that, in addition to the conserved AGGTCA half-site, nucleotides $-1,-2$ and -3 preceding the AGGTCA also conform to the consensus binding site (Fig. 6). Nucleotide -4 , however, differs from the consensus sequence. Comparison of the HS1 with the consensus ROR $\alpha 1$-binding site reveals that positions $-2,-3$, -4 and -6 relative to the AGGTCA motif all 
(A)

OT / ERE

$\Delta$ HS 1

RORE

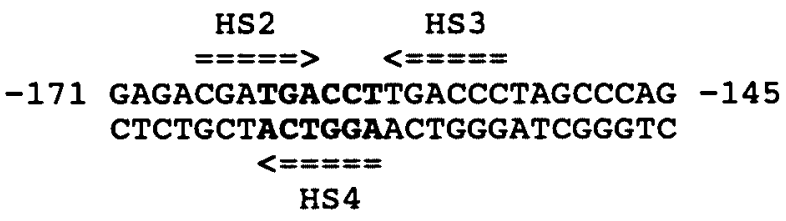

HS2

HS 3

$====>\quad<=====$

-171 GAGACGATGACCTTGACCCTAGCCCAG -145

CTCTGCTACTGGAACTGGGATCGGGTC

$<====$

HS 4

HS2

$=====>$

-171 GAGACGATGACtcgagCCCTAGCCCAG -145

CTCTGCTACTGagctCGGGATCGGGTC

HS1

$====>$

-195 CTTTTGAGTTCCAGGTCATTAGCAGAGA -168

GAAAACTCAAGGTCCAGTAATCGTCTCT

-195 CTTTTGAGTTCCctgcagtTAgCAgAgA -168 GAAAACTCAAGGgaCgLCAATCGTCTCT

$====>$

TCGACTCGTATAACTAGGTCAAGCGCTG AGCTGAGCATATTGATCCAGTTCGCGAC
(B)

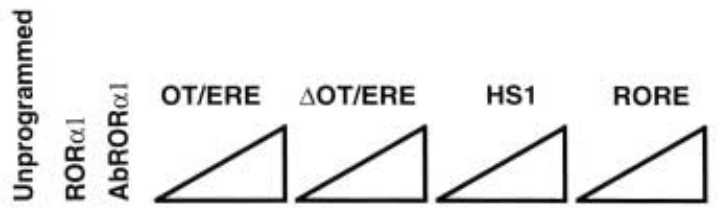

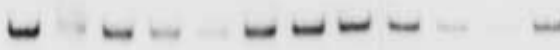

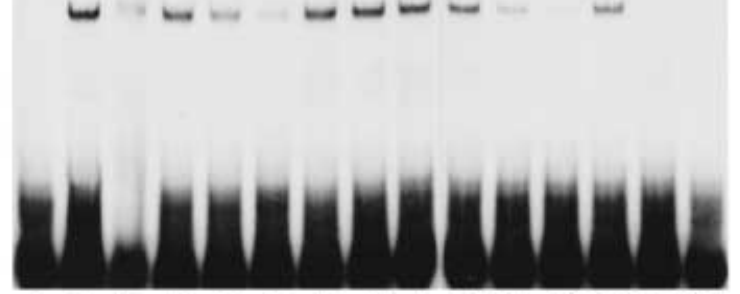

$\begin{array}{llllllllllllllll}1 & 2 & 3 & 4 & 5 & 6 & 7 & 8 & 9 & 10 & 11 & 12 & 13 & 14 & 15\end{array}$
(C)

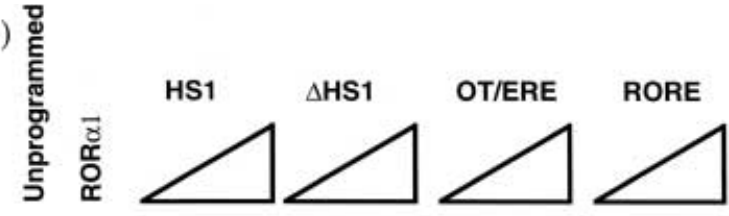

FIGURE 4. EMSAs of ROR 1 binding to the OT/ERE and mutants thereof. (A) Double-stranded oligonucleotides used in EMSA. The OT/ERE with its intrinsic half-sites (HS2, HS3 and HS4 ) as well as the upstream half-site HS1 are shown. (B) In vitro transcribed/translated ROR 1 (lanes 2-15) or unprogrammed reticulocyte lysate (lane 1) was incubated with ${ }^{32} \mathrm{P}$-labeled OT/ERE double-stranded oligonucleotide. Lane 3: coincubation with an anti-ROR 1 antibody. Binding was competed with increasing concentrations (5-, 25- and 100-fold excess) of unlabeled homologous oligonucleotide OT/ERE (lanes 4-6), $\Delta$ OT/ERE (lanes 7-9), HS1 (lanes 10-12), or ROR response element (RORE) (lanes 13-15). (C) As in (B) but the probe HS1 was used instead of $\Delta \mathrm{OT} / \mathrm{ERE}$.

conform to the consensus sequence. Of note is the presence of a $\mathrm{C}$ at position -2 which is conserved throughout in the OT/ERE, the HS1 and the $\mathrm{ROR} \alpha 1$ consensus binding sequence.
Mutation of the OT/ERE or HS1 that abolished binding to ROR 1 reduced ROR 1 -mediated induction by 56 and $68 \%$ respectively and a combined mutation of both the OT/ERE and the 

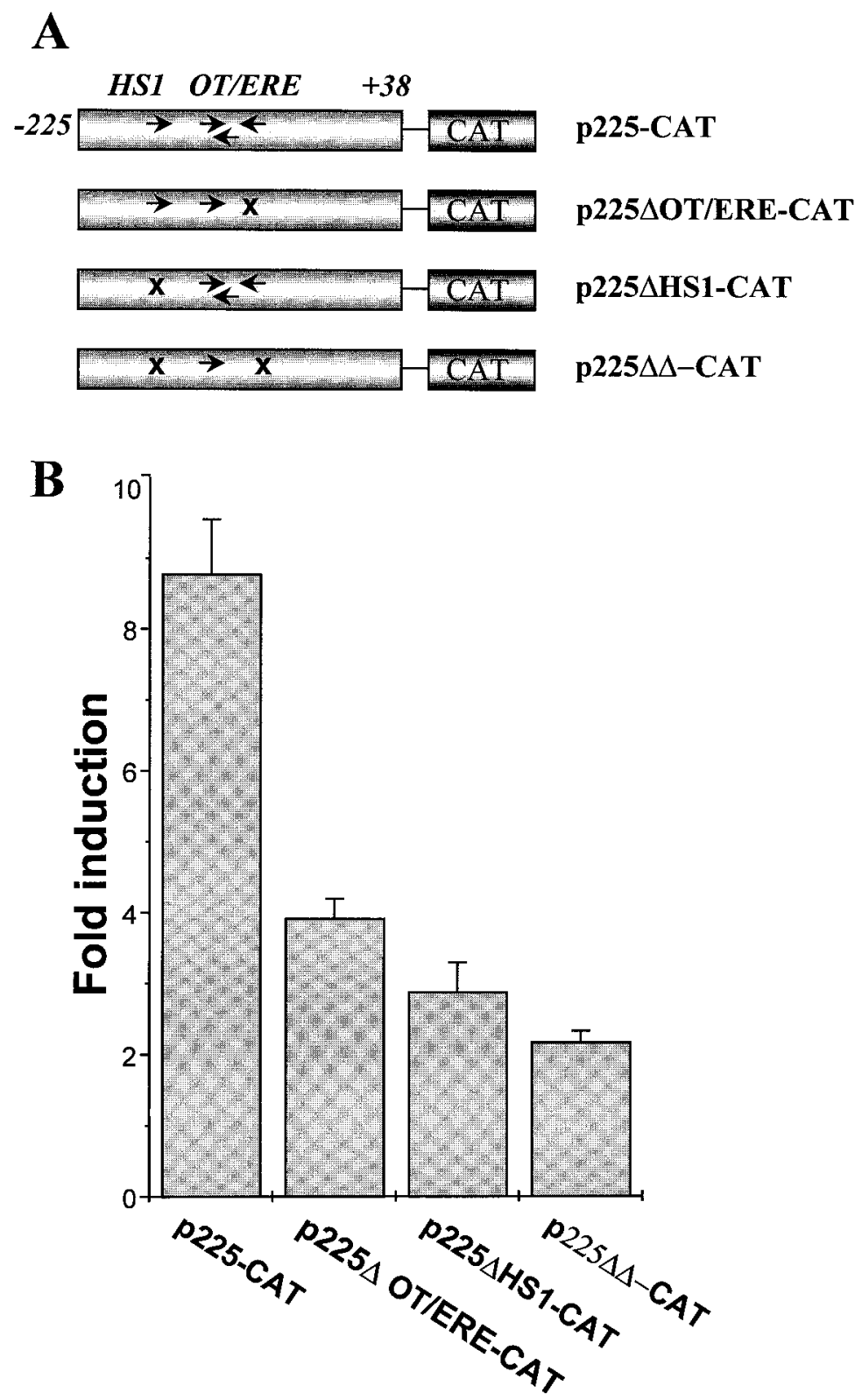

FIGURE 5. Effect of mutations in OT/ERE and HS1 on activation by ROR $\alpha 1$. (A) Schematic representation of constructs used. Mutations were the same as in Fig. 4 and are denoted by ' $x$ '. Half-sites are indicated by arrows. (B) Constructs shown in (A) were cotransfected with the expression vector CMX or CMX-ROR $\alpha 1$ in Neuro-2a cells and CAT activity was determined. ROR $\alpha 1$-mediated transcriptional activation was expressed as the ratio of CAT activity in cells transfected with vector CMX-ROR $\alpha$ vs cells transfected with the parent expression vector CMX. Each bar represents the mean \pm s.E. of three or more independent experiments, each performed in duplicate. 

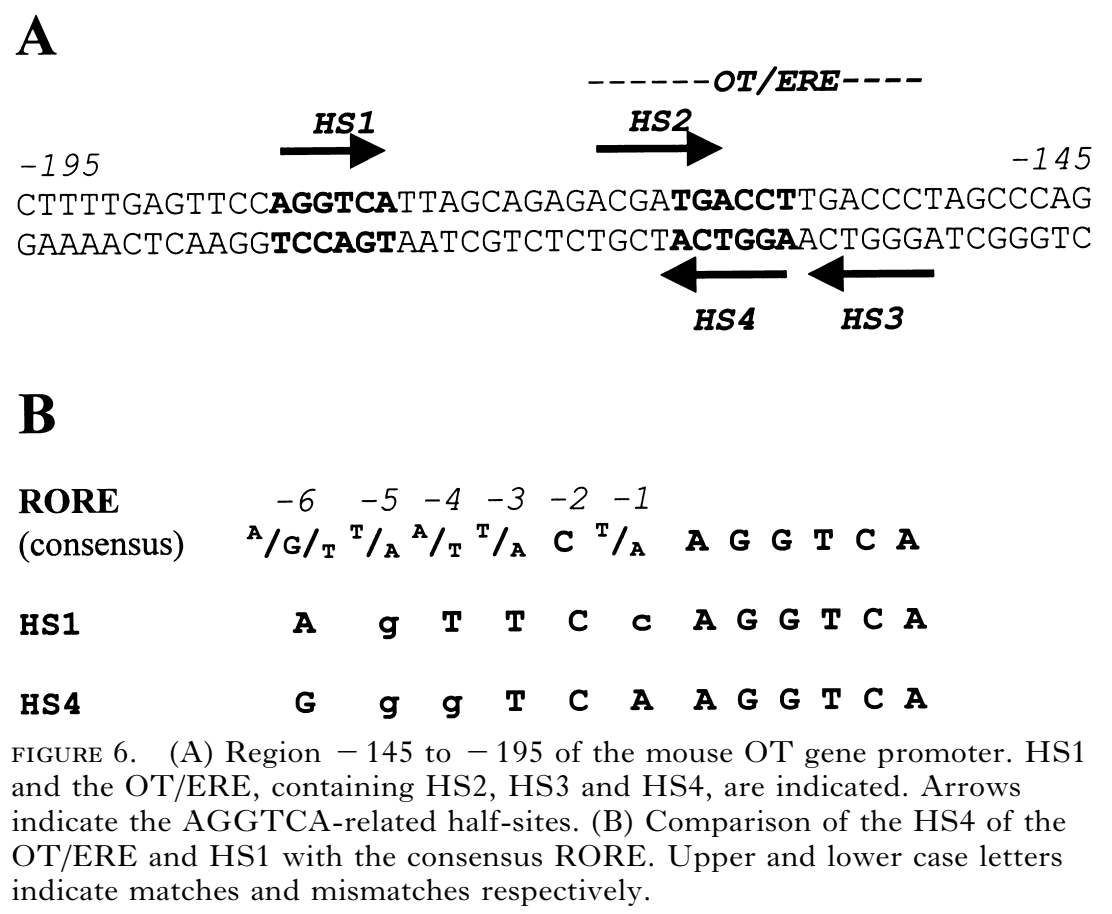

HS1 lowered the induction by $76 \%$ (Fig. 5B). The residual activity of the double mutant is probably due to the downstream AGGTCA repeats, a region which is also weakly protected in the DNAse I footprinting assay.

It remains to be determined to what extent other members of the ROR/RZR family have the same or similar effects on OT gene promoter activity. Studies by Carlberg et al. (1994) indicate that ROR $\alpha 1$ and $\operatorname{ROR} \beta / \operatorname{RZR} \beta$ have indistinguishable binding characteristics and suggest considerable functional overlap between these ROR/RZR isoforms. In view of the expanding list of isoforms present in the ROR/RZR family and the widespread distribution of these members, it is conceivable that interactions similar to the one characterized here for the case of RORa1 may take place in different OT-expressing tissues, involving different ROR/ RZR isoforms. The strong, ligand-independent activation function of ROR $\alpha 1$ demonstrated here suggests that ROR may form an important part of the multifactorial regulatory mechanisms that control the neuronal and non-neuronal expression of the O'T gene.

\section{ACKNOWLEDGEMENTS}

We thank Dr J Battey, NIH, Rockville, MD, USA for supplying us with the plasmid p11.38 containing the mouse $\mathrm{O} T$ gene and Dr V Giguère for giving us the vectors CMX-ROR $\alpha$, HSP- $\beta$-gal and $\beta$-CAT as well as for valuable advice and discussion. We also thank Miss E Monaco for excellent secretarial assistance.

\section{REFERENCES}

Adan RA, Cox JJ, Van Kats JP \& Burbach JP 1992 Thyroid hormone regulates the oxytocin gene. Fournal of Biological Chemistry 267 3771-3777.

Adan RA, Cox JJ, Beischlag TV \& Burbach JP 1993 A composite hormone response element mediates the transactivation of the rat oxytocin gene by different classes of nuclear hormone receptors. Molecular Endocrinology 7 $47-57$.

Becker-Andre M, Wiesenberg I, Schaeren-Wiemers N, Andre E, Missbach M, Saurat JH \& Carlberg C 1994 Pineal gland hormone melatonin binds and activates an orphan of the nuclear receptor superfamily Fournal of Biological Chemistry 269 28531-28534.

Burbach JP, Lopes da Silva S, Cox JJ, Adan RA, Cooney AJ, Tsai MJ \& Tsai SY 1994 Repression of estrogen-dependent stimulation of the oxytocin gene by chicken ovalbumin upstream promoter transcription factor I. Fournal of Biological Chemistry 269 15046-15053.

Carlberg C, Hooft van Huijsduijnen R, Staple JK, DeLamarter JF \& Becker-Andre M 1994 RZRs, a new family of retinoidrelated orphan receptors that function as both monomers and homodimers. Molecular Endocrinology 8 757-770.

Chu K \& Zingg HH 1997 The nuclear orphan receptors COUP-TFII and Ear-2 act as silencers of the human oxytocin gene promoter. Fournal of Molecular Endocrinology 19 163-172. 
Chu K, Boutin J-M, Breton C \& Zingg HH 1997 Nuclear orphan receptors COUP-TFII and Ear-2: presence in oxytocin-producing uterine cells and functional interaction with the oxytocin gene promoter. Molecular and Cellular Endocrinology 137 145-154.

Dussault I, Fawcett D, Matthyssen S, Bader J-A \& Giguere V 1998 Orphan nuclear receptor RORalpha-deficient mice display the cerebellar defect of staggerer. Mechanisms of Development 70 147-153.

Fisher LA \& Fernstrom JD 1981 Measurement of nonapeptides in pineal and pituitary using reversed-phase, ion-pair liquid chromatography with post-column detection by radioimmunoassay. Life Sciences 28 1471-1481.

Giguère V, Tini M, Flock G, Ong E, Evans RM \& Otulakowski G 1994 Isoform-specific amino-terminal domains dictate DNA-binding properties of ROR alpha, a novel family of orphan hormone nuclear receptors. Genes and Development 8 538-553.

Hamilton BA, Frankel WN, Kerrebrock AW, Hawkins TL, FitzHugh W, Kusumi K, Russell LB, Mueller KL, Van Berkel V, Birren BW, Kruglyak L \& Lander ES 1996 Disruption of the nuclear hormone receptor RORalpha in staggerer mice. Nature 379 736-739.

Hara Y, Battey J \& Gainer H 1990 Structure of mouse vasopressin and oxytocin genes. Molecular Brain Research $\mathbf{8}$ 319-324.

Hirose T, Smith RJ \& Jetten AM 1994 ROR gamma: the third member of ROR/RZR orphan receptor subfamily that is highly expressed in skeletal muscle. Biochemical and Biophysical Research Communications 205 1976-1983.

Ivell R, Bathgate RA, Walther N \& Kimura T 1998 The molecular basis of oxytocin and oxytocin receptor gene expression in reproductive tissues. Advances in Experimental Medicine and Biology 449 297-306.

Kunkel TA 1985 Rapid and efficient site-specific mutagenesis without phenotypic selection. Proceedings in the National Academy of Sciences of the USA 82 488-492.

Larcher A, Neculcea J, Chu K \& Zingg HH 1995 Effects of retinoic acid and estrogens on oxytocin gene expression in the rat uterus: in vitro and in vivo studies. Molecular and Cellular Endocrinology 114 69-76.

Lefebvre DL, Giaid A, Bennett H, Lariviere R \& Zingg HH 1992 Oxytocin gene expression in rat uterus. Science 256 1553-1555.

Liu B \& Burbach JP 1987 Characterization of vasopressin and oxytocin immunoreactivity in the sheep and rat pineal gland: absence of vasotocin and detection of a vasopressin-like peptide. Peptides 8 7-11.

Matsui T, Sashihara S, Oh Y \& Waxman SG 1995 An orphan nuclear receptor, mRORalpha, and its spacial expression in adult mouse brain. Molecular Brain Research 33 217-226.
Milcu SM, Pavel S \& Neacsu C 1963 Biological and chromatographic characterization of a polypeptide with pressor and oxytocic activities isolated from the bovine pineal gland. Endocrinology 72 563-566.

Mitchell BF, Fang X \& Wong S 1998 Oxytocin: a paracrine hormone in the regulation of parturition? Reviews of Reproduction 3 113-122.

Richard S \& Zingg HH 1990 The human oxytocin gene promoter is regulated by estrogens. Fournal of Biological Chemistry 265 6098-6103.

Richard S \& Zingg HH 1991 Identification of a retinoic acid response element in the human oxytocin promoter. Fournal of Biological Chemistry 266 21428-21433.

Schräder M, Danielsson C, Wiesenberg I \& Carlberg C 1996 Identification of natural monomeric response elements of the nuclear receptor RZR/ROR. Fournal of Biological Chemistry 271 19732-19736.

Seed B \& Sheen JY 1988 A simple phase-extraction assay for chloramphenicol acetyltransferase activity. Gene 67 271-277.

Steinhilber D, Brungs M, Werz O, Wiesenberg I, Danielsson C, Kahlen J-P, Mayeri S, Schrader M \& Carlberg C 1995 The nuclear receptor for melatonin represses 5-lipoxygenase gene expression in human B lymphocytes. Fournal of Biological Chemistry 270 7037-7040.

Thibonnier M, Conarty D, Preston J, Plesnicher C, Dweik R \& Erzurum S 1999 Human vascular endothelial cells express oxytocin receptors. Endocrinology 140 1301-1309.

Tini M, Fraser RA \& Giguere V 1995 Functional interactions between retinoic acid receptor-related orphan nuclear receptor (ROR alpha) and the retinoic acid receptors in the regulation of the gamma $\mathrm{F}$-crystallin promoter. Fournal of Biological Chemistry 270 20156-20161.

Umesono K, Murakami KK, Thompson CC \& Evans RM 1991 Direct repeats as selective response elements for the thyroid hormone, retinoic acid, and vitamin D3 receptors. Cell 65 1255-1266.

Vu-Dac N, Gervois P, Grotzinger T, De Vos P, Schoonjans K, Fruchart J-C, Auwerx J, Mariani J, Tedgui A \& Staels B 1997 Transcriptional regulation of apolipoprotein A-I gene expression by the nuclear receptor RORalpha. Fournal of Biological Chemistry 272 22401-22404.

Wehrenberg U, Ivell R, Jansen M, von Goedecke S \& Walther N 1994 Two orphan receptors binding to a common site are involved in the regulation of the oxytocin gene in the bovine ovary. Proceedings of the National Academy of Sciences of the USA 91 1440-1444.

Zingg HH 1996 Vasopressin and oxytocin receptors. In Bailliere's Clinical Endocrinology and Metabolism, pp 75-96. Eds MC Sheppard \& JA Franklyn. London: Bailliere Tindall.

RECEIVED 12 May 1999 